\title{
Seismic risk communication: let's students show their own way
}

\author{
Giovanna Lucia Piangiamore ${ }^{1}$, Susanna Falsaperla ${ }^{2}$, Elena Eva ${ }^{3}$ and \\ Gemma Musacchio ${ }^{4}$ \\ (1) Istituto Nazionale di Geofisica e Vulcanologia, Sezione Roma 2, Italy \\ (2) Istituto Nazionale di Geofisica e Vulcanologia, Sezione di Catania - Osservatorio Etneo, Italy \\ (3) Istituto Nazionale di Geofisica e Vulcanologia, Osservatorio Nazionale Terremoti, Italy \\ (4) Istituto Nazionale di Geofisica e Vulcanologia, Amministrazione Centrale, Italy
}

Article history: received November 22, 2019; accepted September 4, 2020

\begin{abstract}
Risk communication has been playing an increasing role in modern society and in our lives. Normally framed to prompt reduction of vulnerability to hazards, it tackles issues ranging from prevention to preparedness and addresses a variety of stakeholders, each with a specific role within a community. However, the way to have the most effective risk communication in the long run is to engage young people: they seed the roots that shape future, increase the potential impact of risk mitigation and help build community resilience. This is the vision that drives the Istituto Nazionale di Geofisica e Vulcanologia (INGV) intervention in the field of seismic risk education. The "Are you taking too many risks?" was a school contest that INGV carried out for the schools involved in the risk communication campaign "Know your school: be safe!" of the project KnowRISK (Know your city, Reduce seISmic risK through non-structural elements) funded by the European Commission DG-ECHO. Students, within a framework of cooperative learning, were asked to develop risk communication tools, being their peers the target public. It was an experiment of public engagement in risk communication that allowed young people to express their point of view and the way they would discuss and approach risks. Cartoons, animated drawings, interviews, and videos showed the way students see risk mitigation, in the age of parkour. The details of each students' product are a lesson learned to shape risk communication campaigns in the future.
\end{abstract}

Keywords: Educational competition; Seismic risk; Active learning; Transformational learning; Prevention; Best practice dissemination.

\section{Introduction}

The role that school plays in disasters' mitigation and in fostering resilience is worldwide acknowledged by agreements that set the international agenda for a substantial reduction of disasters risks (Sendai Framework for DRR 2015-2030). Risk and resilience education make up for one of the three pillars of the Comprehensive School Safety Framework of the United Nations International Strategy for Disaster Reduction, which is a global alliance acting in and for the educational sector (GADRRRES, 2017). Integrated resilience assessments highlight 


\section{Giovanna Lucia Piangiamore et al.}

the fruitful relationship between schools and their community [Shiwaku et al., 2016]. The Istituto Nazionale di Geofisica e Vulcanologia (INGV) is aligned with all these actions by having schools as a priority in the task of promoting a diffuse culture of Disaster Risk Reduction. The rationale behind such actions is that having schools as a focus can drive to a proper understanding of hazard and risk in the whole society and can efficiently implant a process of life-long learning to instill the culture of safety. The school community includes, beside the youth, teachers and principals who can profit from a proper understanding of risk related issues [Mutch, 2015; Bandecchi et al., 2019]. The KnowRISK (Know your city, Reduce seISmic risK through non-structural elements) project addressed the school community as an opportunity to communicate risks related to seismic vulnerability of Non-Structural Elements (NSE) of buildings; these include building contents, architectural elements and mechanical, electrical and plumbing elements [Calvi et al., 2015]. KnowRISK designed and implemented a communication campaign in three European countries. The strategy, the message, the tools, the media, the assessment of the effectiveness of the communication campaign are all summarized in published papers [i.e.: Musacchio et al., 2018a and b; Crescimbene et al., 2018; Reitano et al., 2018; Platt et al., 2018; O’Neill et al., 2018]. KnowRISK was also an opportunity to test new methodologies to facilitate the spreading of prevention's and preparedness' best practices, designed by INGV, that included school contests. For six years (from 2009 to 2015) contests engaged schools in the Province of La Spezia within the ERiNat (Educazione ai Rischi Naturali, "Training on Natural Risks") project. Middle School students (corresponding to the European schooling level ISCDE 2) were asked to show their own way to address, deal with and mitigate natural risks [Piangiamore et al., 2012; 2015; Piangiamore, 2019]. The idea of a competition came from the constructivism theory: when students are asked to actively create their own representations of concepts, ideas, real-life situations, they turn from simple learners into information builders [Neubert, 2001]. Although mental representations are subjective, new information is linked to previous knowledge in new and creative ways, working in groups at home. Selfproduction promotes peer learning as an active, contextualized process of building knowledge rather than just passively acquiring it [Arsalidou et al., 2016; Mutch, 2015; Jenkins, 2010; Borgers et al., 2000].

In this paper we address risk communication in schools by showing students' perspective. The communication campaign "Know your school: be safe!" was centered on a protocol of intervention that describes in details the number of lectures, their length, support material and learning methodology used in the classroom to engage and motivate students. In Italian schools the protocol stood on the flipped learning strategy [The Flipped Learning Network, 2014]. However, for some of the schools involved in the project, this strategy was in turn reinforced by a contest-triggered competition. Italian students were asked to prepare a product to communicate seismic risk posed by NSE that took part of a school contest. Students-made products allow to tackle a peculiar, yet extremely relevant, aspect of a campaign in schools: students' perspective on preventative actions that reduce vulnerability of non-structural elements of buildings is retrieved by looking at the products they deemed relevant to be submitted to the school contest. The goal of looking at students' perspective is to help design future communication items to approach young people and effectively deliver messages.

\section{Methodology}

According to the Institute of Competition Science (ICS), best practices in educational contests allow students to develop intrinsic motivations for the challenges they face with [Reeve and Deci, 1996;

https://www.competitionsciences.org/2016/07/04/10-ways-competitions-enhance-learning/]. Competition could affect motivation, threatening students' sense of competence and self-esteem. In our case, the competition preferably involved the participation of groups of at least two or three people. The group can alleviate the negative aspects of a challenge and increase the reciprocal support [Cardona, 2007] for the common aim to win. Consequently, students worked hard together to boost their specific skills; they also improved teamwork (Collaborative Learning) along with a better understanding of how to deal with conflicting opinions and ideas to work together in spite of differing personalities (Social and Emotional Learning). External incentives (prizes, public recognition, becoming a scholastic hero for peers, etc.) may create a challenge behind the contest, goading students to act for the external reward, and increasing their inborn desire to excel in the contest. The internal sense of competition, which comes from the wish to beat other students, drives them to do better, beyond their own limits [Verhoeff, 1997]. Competition is not the antonym of collaboration because, even though winning is the goal, students have to work hard together 
to boost their specific skills. Setting successive tasks to explore students' increasing skills may help them to appreciate their improving knowledge over time [Dweck, 2006]. Skills of persistence, resilience, and grit are all components of mental toughness, thus educational competitions allow students to practice these skills, discovering how to bend and not break under pressure, and how to handle stressful situations through participation. Losing is not the end, but just a step of an amazing learning experience. Protecting students from failing can disadvantage their future careers. Following Yeager and Dweck [2012], educational competitions can be hence considered a training for their future jobs.

Given the premises, we designed a school contest titled "Are you taking too many risks" to reinforce the effectiveness of the risk communication campaign "Know your school: be safe!". The campaign stood on a specifically implemented protocol that used Situated Learning Episode [EAS, Episodio di Apprendimento Situato; Rivoltella, 2013] which is a flipped-learning strategy that can be defined as: the "pedagogical approach in which direct instruction moves from the group learning space to the individual learning space. The resulting group space is transformed into a dynamic, interactive learning environment, where the educator guides students as they apply concepts and engage creatively in the subject matter" [The Flipped Learning Network, 2014; Dunn, 2014; Bergmann and Sams, 2012]. The EAS strategy was already applied to natural hazards education and precisely to implant best practices on preparedness [i.e.: "There is an earthquake! What to do?", "Earthquake and tsunami: what should I do if I am outside?" and "Floods: what to do?" in Piangiamore et al., 2016]. Thus, we set up an innovative disaster educational tool based on a specifically designed EAS named KnowRISK-EAS which required the incorporation of the focus group method, at $\mathrm{T}_{0}$, in the preparation- and at $\mathrm{T}_{1}$ in the debriefing-phase (Figure 1 ). The focus groups were carried out by experts (researchers and fire brigades) in the classroom - one class at a time - to trigger discussion on seismic risk prevention.

The $\mathrm{T}_{0}$-focus group lasted about 2 hours and was held by seismologists with the goal to clarify the difference between hazard and risk and to explain key scientific concepts. It was followed by a fire brigades' intervention that had an Emotional Learning approach. Fire brigades showed slides on disasters caused by earthquakes in Italy. They made use of the story-telling technique centered on their personal experience. They brought to class the awareness of the earthquake and the personal feelings of those involved in it. The focus group was also designed to stimulate students to prepare, at home, products on mitigation of non-structural damage. The preparation of these products was done in small groups to profit of a cooperative learning strategy.

The $\mathrm{T}_{1}$-focus group was the conclusive activity: students commented with their classmates their products and discussed with scientists even new more actions to prevent seismic disaster [Piangiamore et al., 2017b].

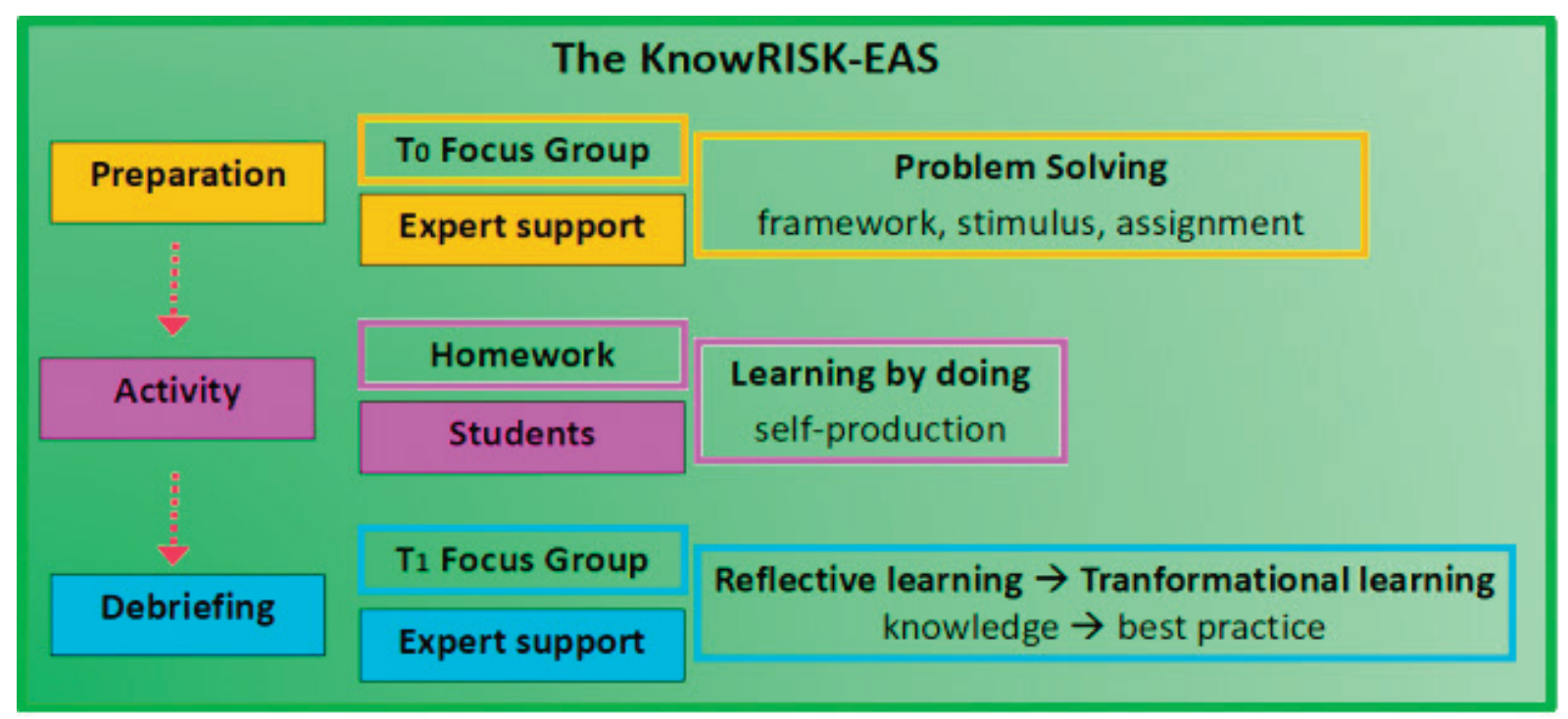

Figure 1. The KnowRISK-EAS scheme: the three phases that delineate the experts' and students' actions corresponding to three distinct learning strategies, namely problem solving, learn by doing, reflexive learning. The focus groups at $\mathrm{T} 0$ and the $\mathrm{T} 1$ bound the creative phase of the EAS, when students make their self-products. 


\section{Giovanna Lucia Piangiamore et al.}

\section{Application}

The contest involved 49 teams of 2-4 students in competition coming from 19 different classes. In particular, 16 classes of $3^{\text {rd }}$ grade Middle schools and 3 classes of Lyceum $1^{\text {st }}$ grade (Table 1$)$.

Within the KnowRISK-EAS students were asked to implement a tool for risk communication; target public were young people in their same age; the content had to be mitigation of damage to non-structural elements caused by earthquakes. Student's products were Videos, Cartoons, Interviews, Presentations, Graphics (slogans, comics, posters, flyers), Plan (to school or class, in a home or a room in particular), Brochure, Poetry, Song, and Music. They showed students' point of view and allowed us to test the effectiveness of assessment of the KnowRISK-EAS, by analyzing the development of students' critical thinking and analyzing skills improved by the KnowRISK experience. These skills are an integral part of education, helping young people become responsible, caring, and contributing citizens. To win the "Are you taking too many risks?” competition, students were required to: i) examine seismic risk considering non-structural elements in real-world situations, ii) determine a course of action to provide a safer environment, and iii) convey a message to their peers (and adults in general) to spread their designed solutions. This was a rare opportunity to develop students' skills to assess risks in their environments, at home or at school, in order to design appropriate solutions. In this way, students could be better prepared for possible future earthquakes, cultivating their growth mindset according to Dweck [2006] to become proactive citizens. The students' creations had to balance the artistic and the scientific elements in order to communicate an incisive message on the reduction of the non-structural seismic risk, perhaps summarized in a slogan, combining pertinent artistic techniques and methods to design a compelling work to capture the public's attention. Students' products were assessed by 15 jury members (scientists, school teachers, pedagogists, and experts in science communication) according to the evaluation criteria of theme enhancement and content quality, creativity and capacity to develop the project idea, technical quality of the outcome, aesthetics and originality of the presentation, expressive effectiveness, interdisciplinarity of the product and its contents (see appendix for details).

\begin{tabular}{ccccc} 
& \multicolumn{2}{c}{ Middle Schools (ISCDE 2) } & & \\
Location & Name & $\mathrm{N}^{\circ}$ Teams & Classes Level & $\mathrm{N}^{\circ}$ Students \\
\hline La Spezia & J. Piaget & 11 & III & 78 \\
\hline La Spezia & U Mazzini & 12 & III & 32 \\
\hline Lerici (La Spezia) & F. Poggi & 10 & III & 46 \\
\hline S. Terenzo (La Spezia) & P. Mantegazza & 2 & III & 6 \\
\hline Laveno Mombello (Varese) & G. B. Monteggia & 8 & III & 28 \\
\hline Location & High Schools (ISCDE 3) & Classes Level & $\mathrm{N}^{\circ}$ Students \\
\hline Sarzana (La Spezia) & Name & N ${ }^{\circ}$ Teams & I & 15
\end{tabular}

Table 1. Schools engaged in the "Know your school: be safe" risk communication campaign that took part to the "Are you taking too many risks?” competition.

\section{Results}

Traditional schooling system generally leaves scarce opportunities for students to practice critical thinking, analyze results of their learning processes, make improvements or determine a new course of action [Abrami et al., 2015; Uksw, 2014; Almeida and Rodrigues Franco, 2011; Osborne and Dillon, 2008]. Thus, we set up a competition to prompt students to determine a course of action under the supervision of researchers and teachers, who guide them promoting the development of best practices and strong self-motivation. The KnowRISK contest "Are you taking too many risks?" was a way to promote alternative/progressive Human-Centred Education (HCE) practice, enhancing the intrinsic value of the students' personality and their well-being, focusing on their human qualities (interest, curiosity, care, relationship, and responsibility), and putting youths at the center of their educational 
process. In this contest, teachers, researchers, and experts are scaffolding having the important role to assist students in carrying out the assigned tasks, being counselors who promote the autonomy of individuals, and foster their creativity and imagination (https://humancentrededucation.org/). This radical change of perspective in the learning process favors the use of the experience that leads to a spontaneous final group reflection [Torosyan, 2007]. The competition allowed us to test the KnowRISK-EAS, demonstrating that it is a valid educational tool for seismic risk reduction, as it applies a new didactic methodology for a modern digital school able to disseminate correct information, reflect on misconceptions, spread best practice between the youths through peer-to-peer communication. There were five winning teams (some of them of the same school and equal in score with others), so the three cash prizes were awarded to three different schools among the participants as per regulation. A further recognition was the attendance at the final meeting of the KnowRISK project in Lisbon presenting the point of view of the Italian students and taking an active part in the round table with the stakeholders.

\section{"Student's own way": a different perspective}

In the examples in Figures 2, 3, 4, 5, 6, 7, 8, 9, and 10 students highlighted their own view on what adults, scientists, firefighters, and teachers had to say about non-structural seismic vulnerability.

The first classified of the winners' contest (Figure 2) is a bilingual animated drawing: comics are written in English and flow as a cartoon, while storytelling is in Italian. The earthquake is personified by Mr. Spring and resembles the shaking that a building must stand and resist. Mr. Spring knows its own effects and can tell you what to do in your house to mitigate damage. The use of the spring is a winning idea: it's elastic, thus it well represents the seismic wave propagation, but also it can be considered the metaphor of resilience, which is defined as "the ability to bounce back to normal after experiencing pressure". The images of a bookcase that topples, or of objects that can fall from a shelf and hurt you, or of who stumbles and falls while running away are simple, yet effective, icons that students decided to convey for a special attention to their peers. The choice of these images involves the use of creative pictures and drawings, which can communicate a far better understanding of the key concepts. The students' choice to write cartoons in English highlights their will to communicate not only with their Italian peers, but also with anyone in the world. This is not the only example of a comic book entirely made by the students (drawings and texts), but that of Figure 2 has certainly turned out to be the most beautiful and the most effective.

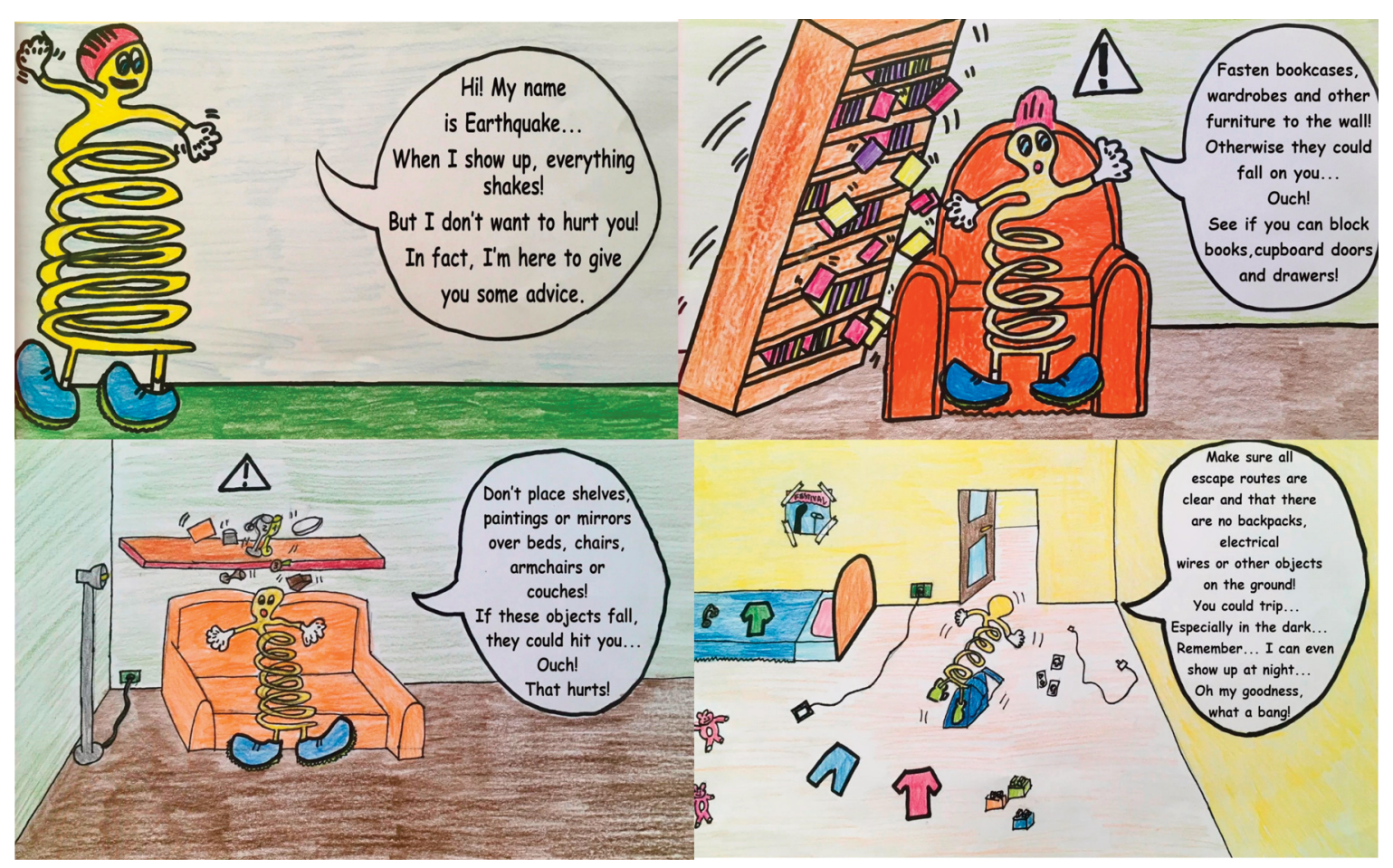

Figure 2. The first classified product: an animated drawing to learn best practice to reduce non-structural damage (credits: Middle School “U. Mazzini”, La Spezia). 


\section{Giovanna Lucia Piangiamore et al.}

The second classified (Figure 3) is an interesting example of video scribing, a visual thinking technique gaining popularity due to its uniqueness, and power of delivering a message. The video starts from a mind mapping of seismic reduction knowledge.

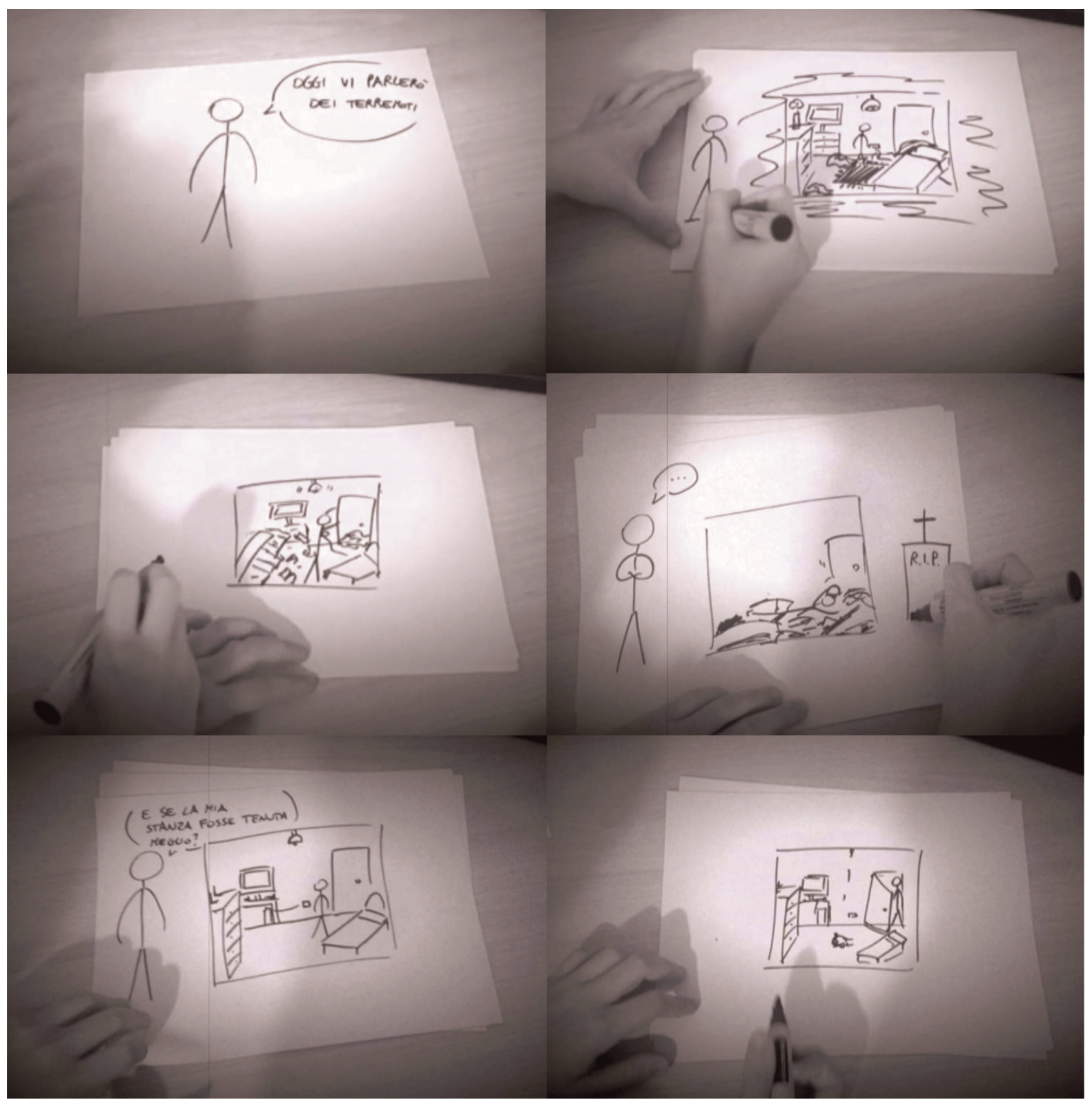

Figure 3. The second classified product: a video scribing to reflect on possible non-structural damages and prompt behavior to remove them (credits: Middle School “J. Piaget”, La Spezia).

The concepts are available in a visual form through a series of animated drawings that make them easily accessible, help understanding, keep attention alive, and allow the message to be memorized. It begins with the statement: "Let's talk about earthquakes", then shows us the image of a tomb and continues with the thought: "If my room had been tidier (and safe)!", as well as a series of other useful reflections on the importance of safe behavior in case of an earthquake. Other videos in the "Are you taking too many risks?" competition was made with the technique of video scribing, but this one turned out to be the most beautiful artistically.

The other (equal merit) second classified product is an original example of effective communication, where modern and old techniques - such as the classic Italian cartoon "The line" by Osvaldo Cavandoli - convey a message 
capable of explaining serious subjects with lightness and simplicity, gaining interest and attention of new audiences. The little man part of a (virtually infinite) line is redrawn by students and involved in an earthquake. He has to solve the problem of not-structural damage and has not to argue with his wife. "Prevention not only saves live ... but improves it!" (Figure 4).

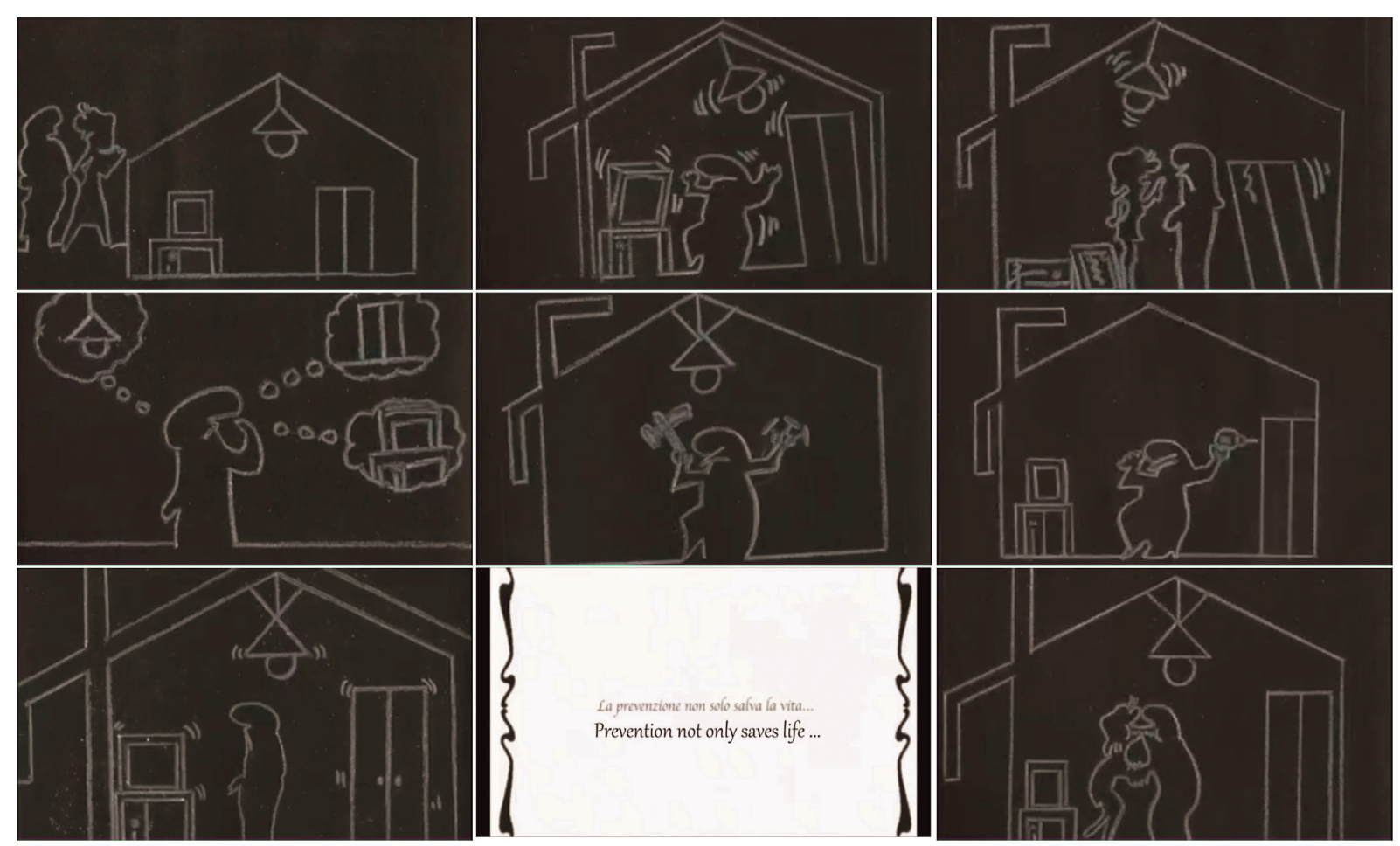

Figure 4. The other second classified product: a students' drawing cartoon inspired to the Osvaldo Cavandoli’s “The line” in an earthquake setting (credits: Middle School “U. Mazzini”, La Spezia).

This is the unique product that combines technical specifications to rearrange your home in order to avoid nonstructural damage meanwhile the cartoon entertains and makes you smile.

The third classified is an animated comic, a visual narrative product that combines illustrations and digital animation, synthesizing in a funny way the content of a lesson on non-structural damage and safe behaviors in a bedroom and in a classroom (Figure 5).

All of the above products make use of the story-telling technique, a successful practice in the field communication that here is spontaneously chosen - i.e. without the knowledge of it- by the students. The framework, the environment and the characters chosen by the students are a valid help to design risk communication tools.

Many teams of students have chosen a handmade house model to capture attention on seismic risk reduction (some examples in Figure 6). Their videos adopt different strategies: some of them describe the preparation of the model at each stage; others explain and demonstrate, by means of bedroom models with original tutorials, how to solve problems of seismic risk mitigation by suggesting creative and common-sense solutions. They often use dummies to simulate the real risk to be hurt ( Figure 6 top left).

Different types of interviews illustrate the student's vision dealing with the problem of promoting resilience and safety practices. The strategies to capture attention on non-structural elements are quite different, but students convey precise and synthetic messages, which interest the user and enrich his/her knowledge (Figure 7). Questions are representative of what the students think we should be saying to the public in order to convince that risk mitigation actions should be undertaken. They also stress the importance of presenting solutions that can be pursued by common citizens. 

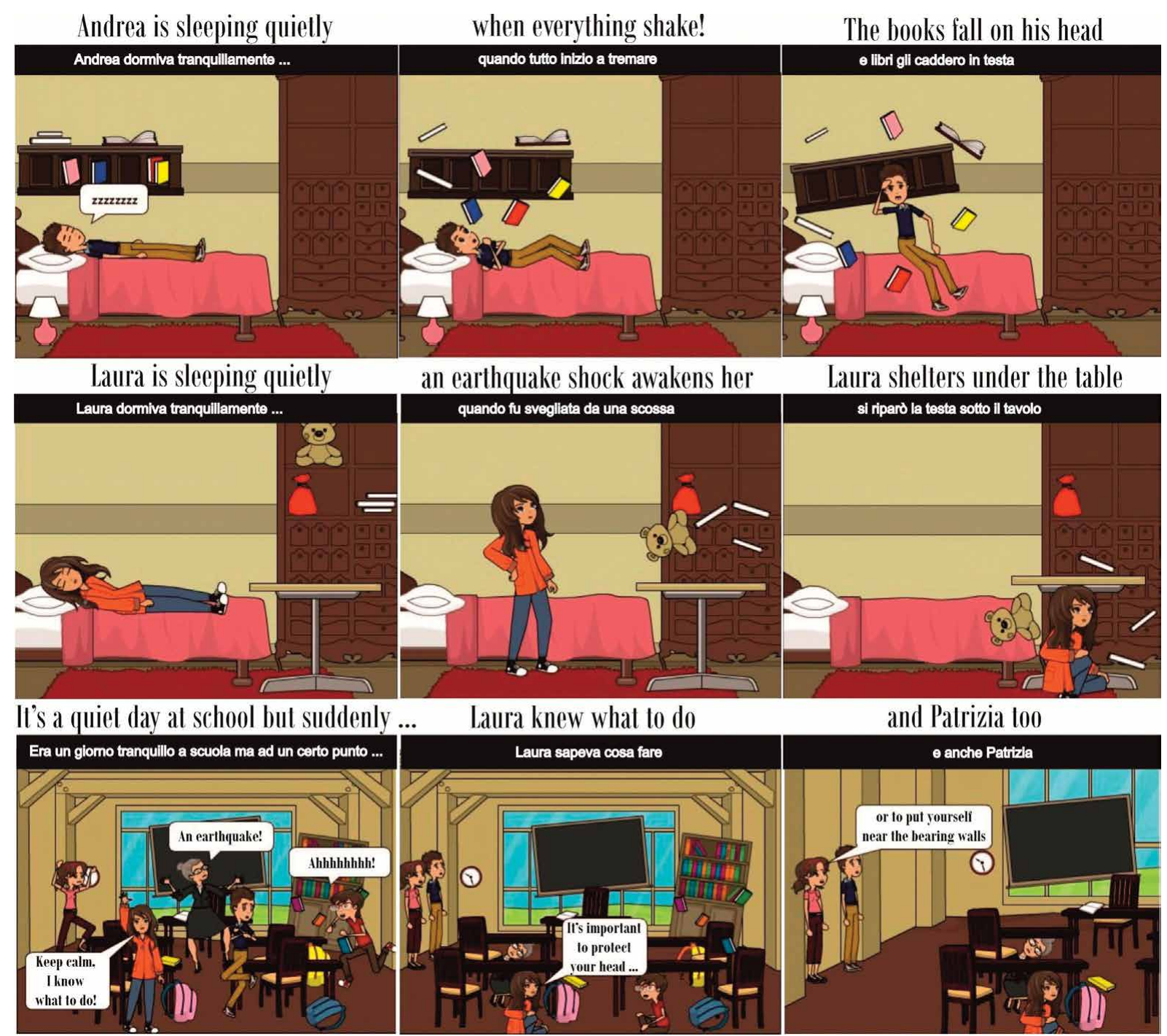

Figure 5. The third classified product is an animated comic (credits: Middle School “G.B. Monteggia”, Laveno Mombello, Varese).

Combining communication and learning, students apply different visual thinking techniques, in which the clarity of the message is a fundamental element to engage the public. Figure 8 shows virtuous behaviors outside (e.g., reach an open-space, away from buildings, and non-structural elements that could fall), indoor (e.g., shelter under a table or a desk), and offers examples of dangerous behavior outside (e.g., never take refuge under a balcony: it could come ruinously down!) and indoor (e.g., not rush towards the stairs: they could collapse; never get under a bookcase: always seek shelter!).

Figure 9 shows examples of how students approach people that are not necessarily peers to them. We portray two different products: (1) warning message to the general public and (2) a support item for a decision maker. Students thought that general public can be easily caught by a slogan and they framed the slogan as a road sign (Figure 9 right).

The second product is a part of a technical report. The students of an entire class made a vulnerability assessment checklist that looks almost professional. They thought this could be the way to approach a decision maker. In groups, they analyzed the various spaces of the school building and made a technical report. The report is extremely detailed. In each form, they drawn the plan of the room and highlighted, with photos and explanations, the criticality of each room based on the position and the vulnerability of the non-structural elements. The message of the technical report is addressed to the school manager and the stakeholders who can act to reduce the non-structural seismic risk in the school. They thought they have to proof the vulnerability of the elements in order to convince the decision maker. 
Risk communication: the students' way

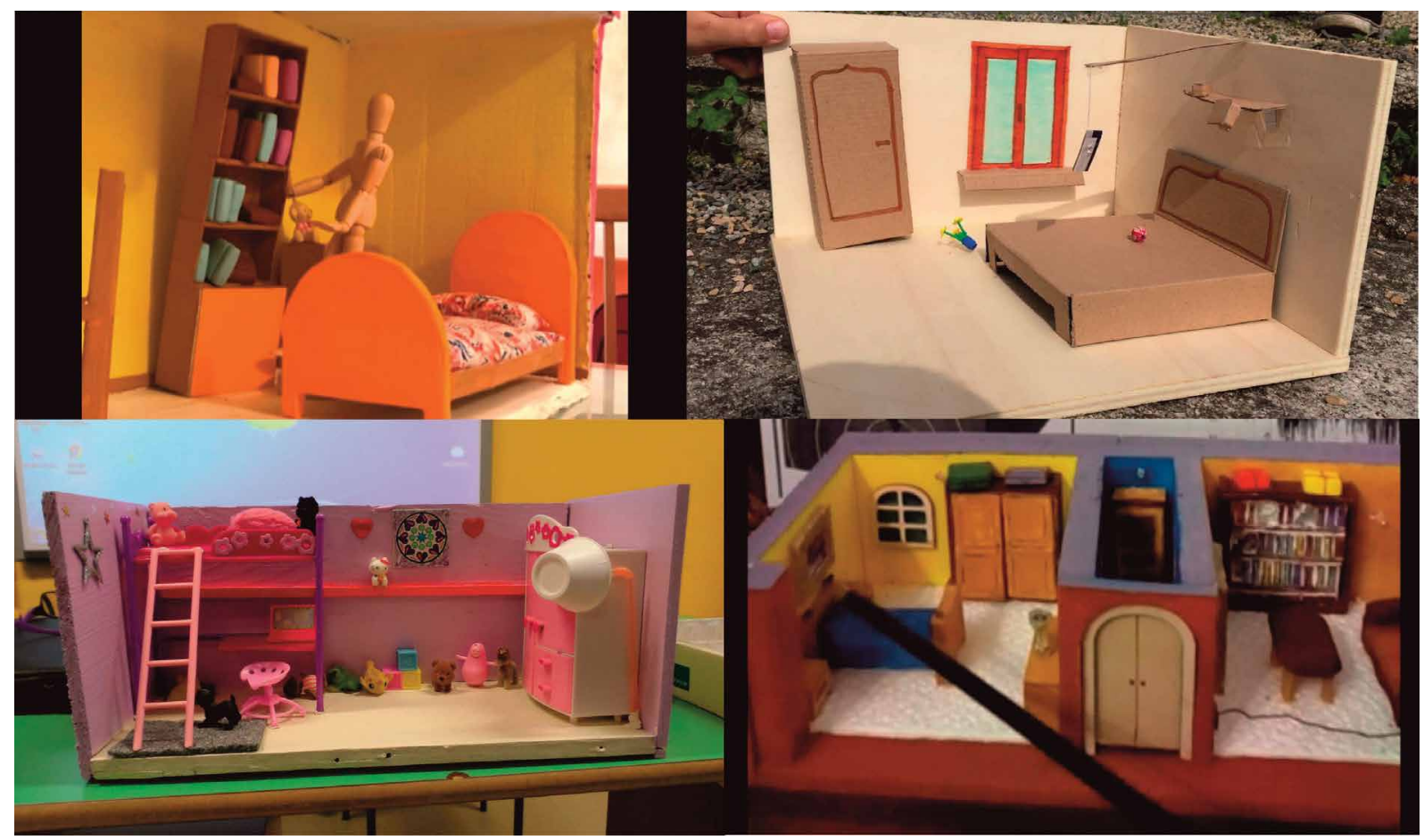

Figure 6. A selection of images from videos of bedroom and house models after simulating an earthquake (credits: Middle School “F. Poggi”, Lerici (SP), bottom left; Scientific Lyceum (ISCDE 3) “Parentuccelli-Arzelà”, Sarzana (SP), top left and right; bottom right).

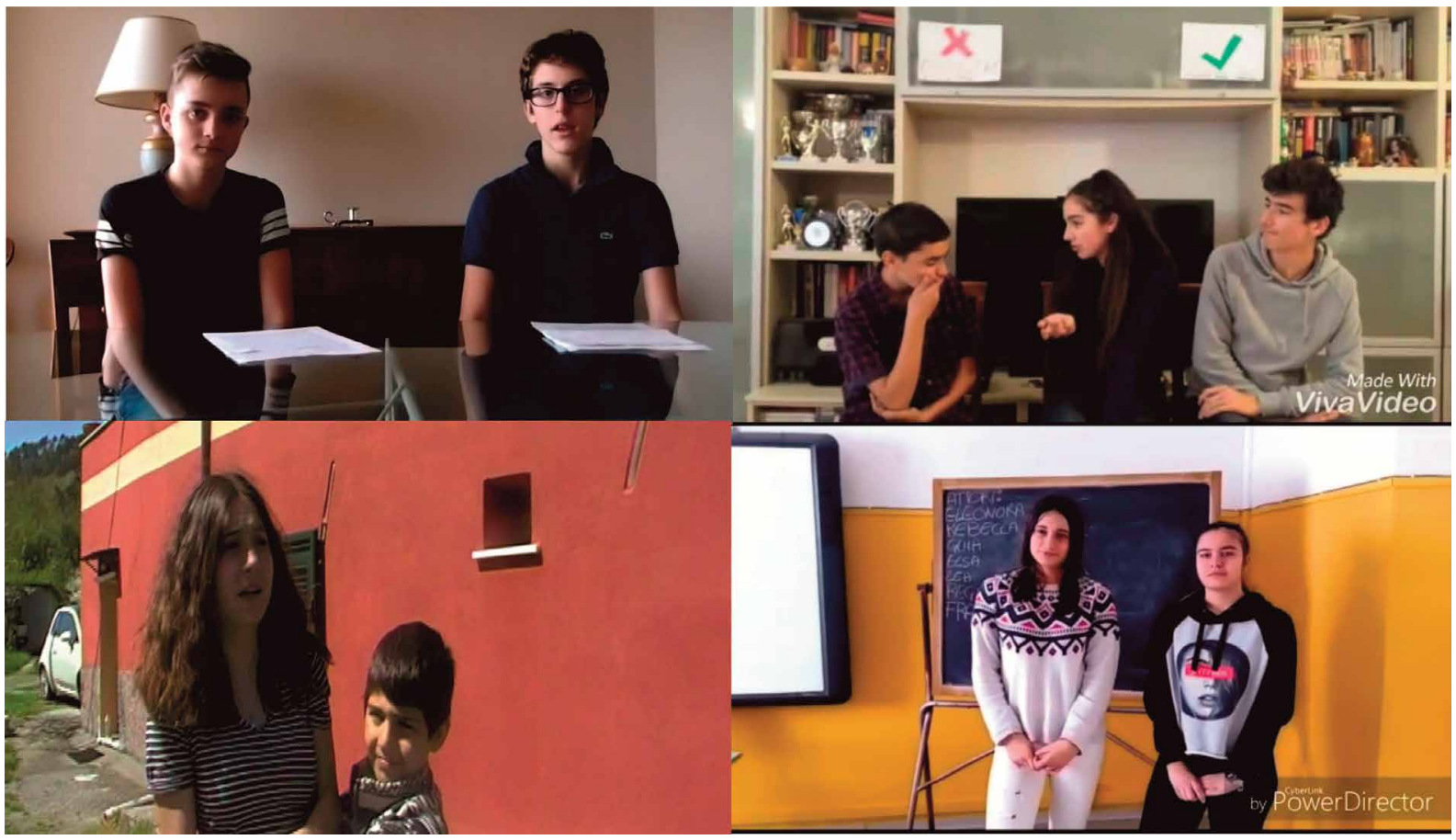

Figure 7. Example of different type of interviews. Newscast with TV studio interviews:an expert (top left) and victims of an earthquake (top right). Interview outside a building after evacuation (bottom left) and of students about risktaking behavior at school (bottom right). Credits: Middle School “U. Mazzini”, La Spezia, top left; Middle School “P. Mantegazza” San Terenzo (SP), top right; Middle School “J. Piaget”, La Spezia, bottom left; Middle School “F. Poggi”, Lerici (SP), bottom left. 


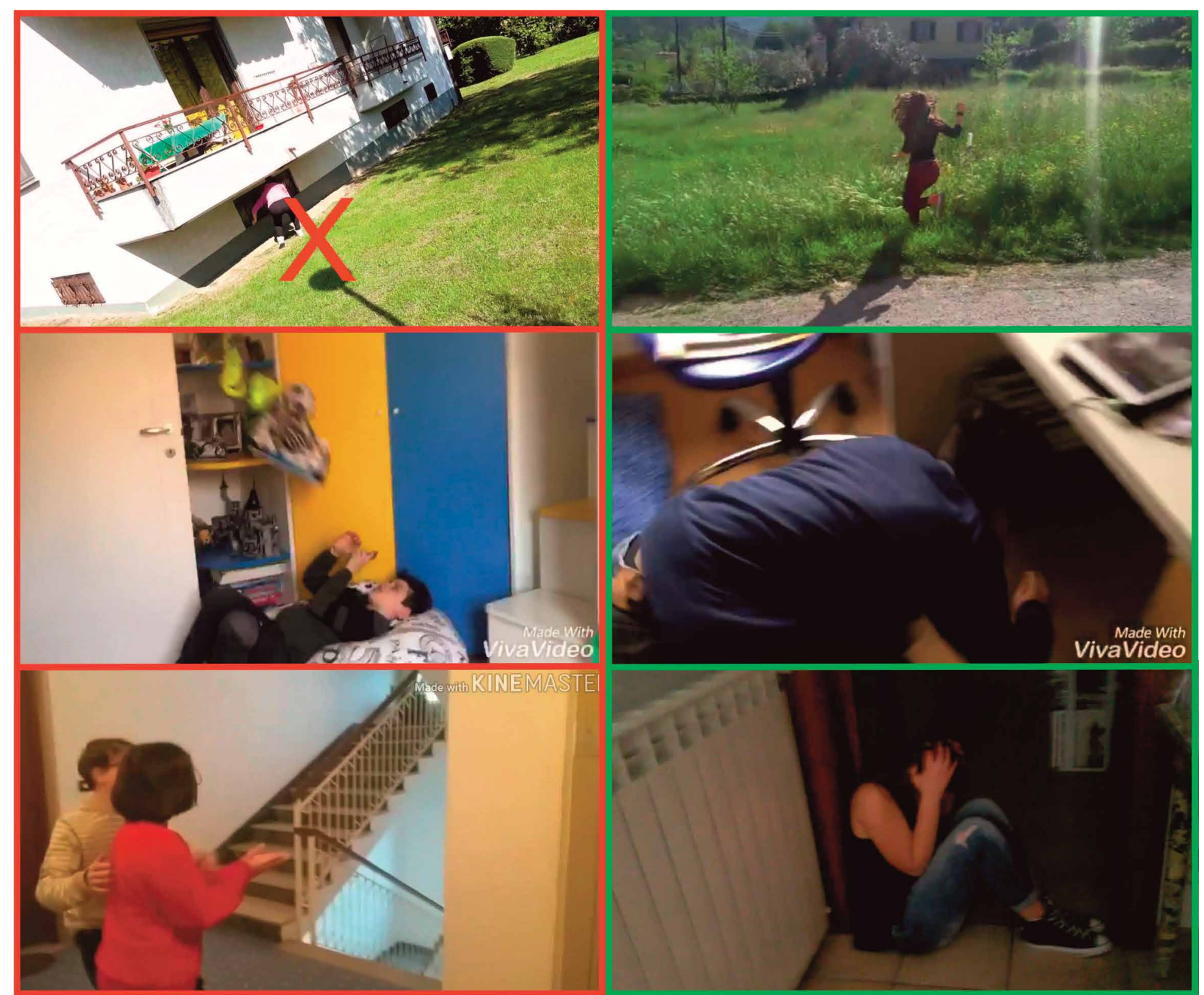

Figure 8. Example of different uses of videos made by students to convey important safety behavior messages in case of earthquake. The snapshots show incorrect behavior (in red, on the left) and correct behavior (in green, on the right). Credits: Middle School “G.B. Monteggia”, Laveno Mombello (Varese), top left; Middle School “F. Poggi”, Lerici (SP), middle and bottom left, middle right.
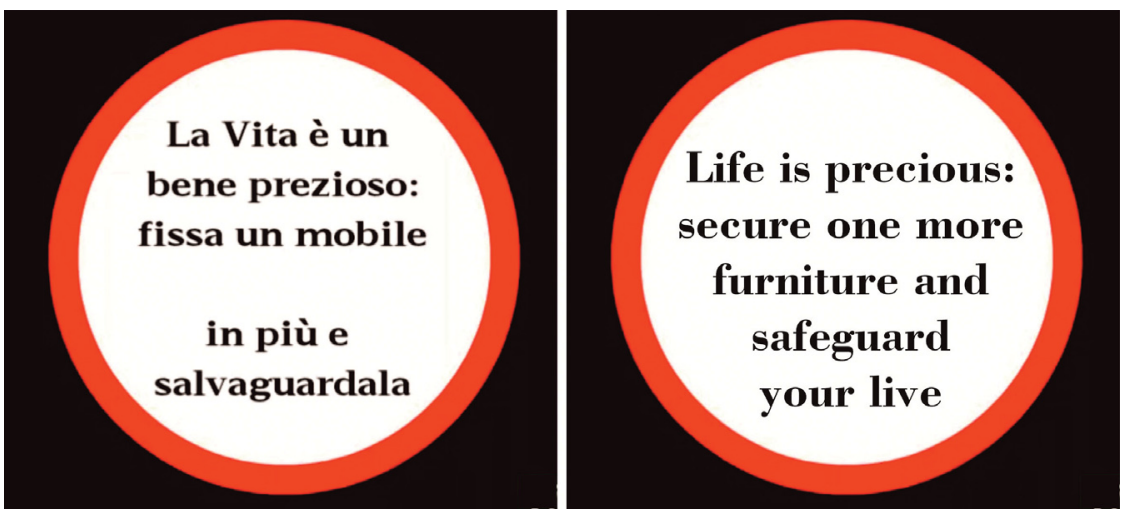

Figure 9. On the left, part of a technical report form prepared by the students for the whole school. On the right, an example of effective seismic risk reduction message: the very clear key message at the end of a short presentation. Credits: Middle School “J. Piaget”, La Spezia (both). 
In this paper we have presented only a few examples of the seismic risk reduction messages and games we collected in the contest (see Table 2). The card game shown in Figure 10, conceived by the students, is inspired by a well-known card game in vogue among young people of that age group. The real card game is derived from the analogous imaginary game that appears in a manga. It includes three main types of cards: Monster cards, Magic cards and Trap cards. Through the summoning of Monster cards, players try to damage the opponent, helped by the powers of Magic cards and Trap cards. Figure 10 depicts the monster cards designed by the students, presenting both an attack and a defence value. The cards offer a collection of targeted instructions, such as "fasten metal squares to the sides of a cabinet to avoid toppling in case of an earthquake; the additional fastening system of the cabinet doors is also useful for your safety”.

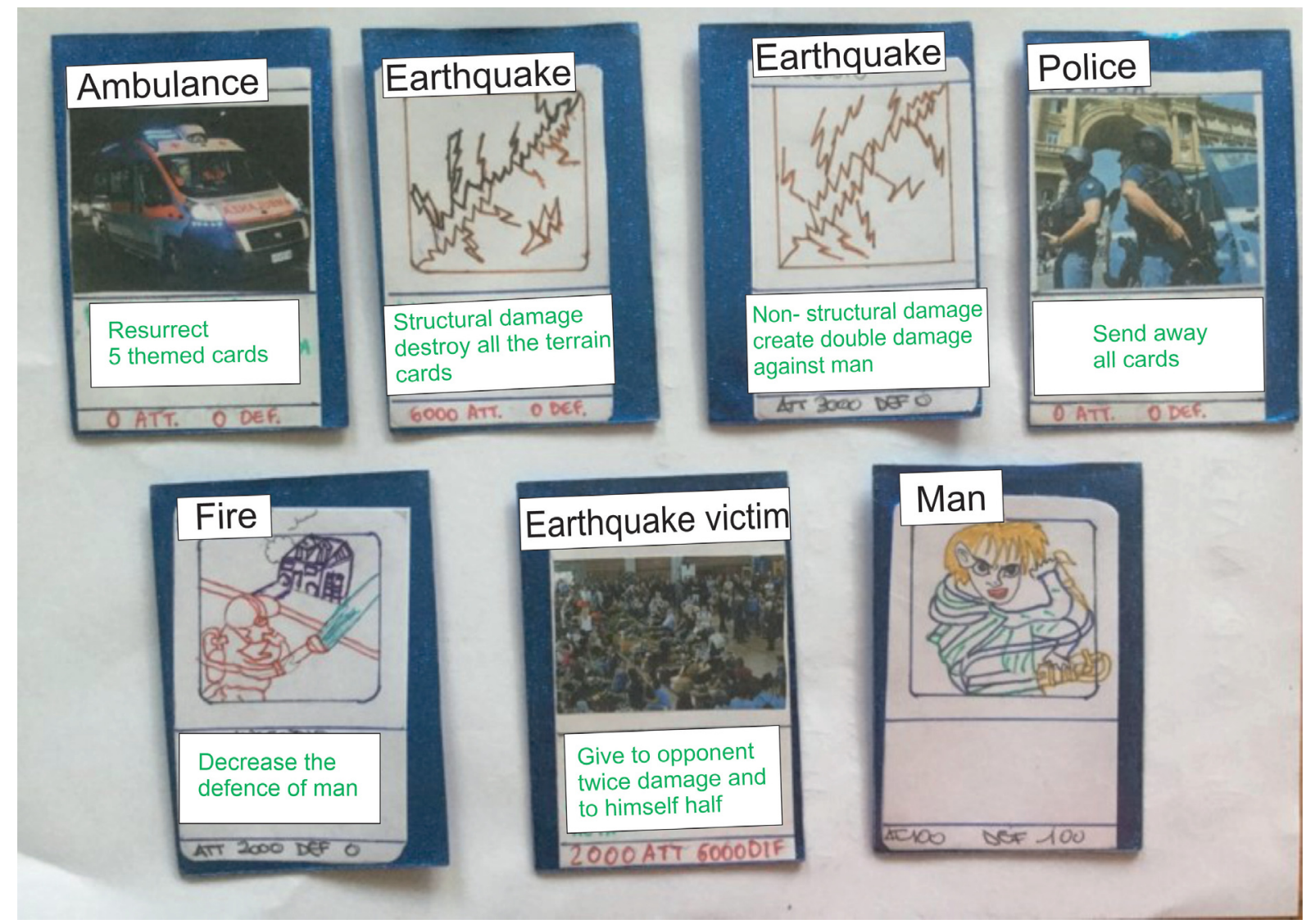

Figure 10. Monster cards of a game, conceived by the students, inspired by a well-known card game. Credits: Middle School “J. Piaget”, La Spezia.

Stimulating suggestions also come from the videos, which lead everyone to think on possible non-structural damage, best practice, and prompt action to remove it, highlighting the importance to fix a picture or a mirror to the wall, as well as use small and inexpensive devices to save our life. Also, well-designed Power Point, Prezi, and PowToon presentations, in particular one of a virtual peer-to-peer lessons, contained useful suggestions. This mix of techniques was customized with different graphic styles. This made each students' product unique and original, ready to communicate its immediate message.

We collected 93 students' original products during the KnowRISK project as the result of the homework of the KnowRISK-EAS (Table 2) and 49 of them took part in the KnowRISK contest "Are you taking too many risks?".

We had five winning teams (some of them of the same school and equal in score with others), so the three cash prizes were awarded to three different schools among the participants as per regulation. As further recognition, a winning team attended the final meeting of the KnowRISK project in Lisbon to present the point of view of the Italian students taking an active part in the round table with the stakeholders. 


\section{Giovanna Lucia Piangiamore et al.}

\begin{tabular}{lc} 
Type of product & quantity \\
Cartoons & 2 \\
\hline Videos & 22 \\
\hline Interviews & 6 \\
\hline Videos scribing & 2 \\
\hline Songs & 3 \\
\hline Power Point Presentations & 23 \\
\hline Animated images & 6 \\
\hline Posters & 4 \\
\hline Prezi Presentations & 6 \\
\hline Poems & 2 \\
\hline PowToon presentations & 2 \\
\hline Short films & 4 \\
\hline Games & 2 \\
\hline Technical reports & 1 \\
\hline Scale models + video & 8 \\
\hline
\end{tabular}

Table 2. Products prepared by the students within the KnowRISK-EAS are listed by type.

\section{Conclusive remarks}

As education plays a key role in shaping a more resilient society, Transformational Learning is the learning style that best support people in changing, in the long run, their dysfunctional means of seeing the world. Keeping this in mind, we designed the school contest "Are you taking too much risk?" that involved students in the last year of Middle Schools and in the first year of High Schools (European schooling level ISCDE 2 and 3). The competition is the steering activity sealing the first phase of "Know your school: be safe!" risk communication intervention in schools. The results we have obtained are a clear demonstration of the potential for Transformative Learning among all students, beyond those who are predisposed to engage in extracurricular voluntary activity [Bamber and Hankin, 2011; King, 2005]. The experience of the educational competition has also provided a useful basis to explore way to combine learning with what is a meaningful service for a community, in other words "Service Learning”.

The competition provided insights into the learning strategy to capture attention of young people and turn them into an influential audience. Focus groups were the mean to trigger reflexive learning and exchanging different points of view but also a way to assess the effectiveness of the risk communication intervention. The students were challenged with tasks that required good communication and cooperation. The fact that they strived to achieve such tasks made them work harder at understanding not only their specific skills, but also how to work well all together. Also, as students of a team knew other teams aimed at the same goals, moved them to become more cohesive, improving their overall skills of risk analysis [Lam et al., 2004].

A group of students had also the opportunity to reflect together with experts about the relevance of damage of non-structural elements. This opportunity also allowed them an exchange of experience rich of games and practical activities made by Italian and Portuguese researchers for the visit of the 3E class of the "J. Piaget" pilot school of La Spezia to Lisbon for a peer-education experience with the students of “Padre António Vieira” school. The request to do this scientific twinning started from the Italian teachers about the project activities. They organized the final trip of the third class to Portugal by inserting the scientific activities agreed between INGV and IST (Instituto Superior Tecnico of Lisbon). The presence of students and teachers from foreign countries allowed them to open a debate together with researchers involved in the KnowRISK project about the topics presented comparing the different protocols of action in the two countries. The task to design a competitive, original team-product to be the 
winners pushed the students to strengthen their understanding of basic scientific concepts, learn new ones, and improve the speed at which they solve problems. Accordingly, we promoted problem solving and other skills. Teams could be in competitions with other teams of the same classroom or other classrooms of the same school or other schools of the same city, and so on. "Little else gets a group of young people more energized than competition", as says Shindler [2009]. To improve the development of learning skills, practice is the key of success. Students are always enthusiastic to practice what they learn, but we, as competition makers in this case, had to avoid potential problems that could derive from the authority of the teacher. We choose flipped-learning to provide education on risk mitigation in a more effective way.

Often disasters occur because of an inefficient prevention and preparedness. Our case study demonstrates that students - as main actors of a preventative message - can offer a sustainable way to provide a meaningful service to society. The students enrolled in our team-based educational competition were able to become advertisers, conveying effective seismic risk reduction messages in an original and very impressive way. Several products have surprised the jury for the power of their way to communicate, their quality, the potential to implement innovative ideas by means of different communication strategies and techniques. Of the nearly 700 students involved in the campaign "Know your school: be safe!" more than 200 of them took part in the contest and got engaged in cooperative and debate learning activities. If we consider that each class involved in our project could submit to the contest not more than three products, we can conclude that the participation was about 30\%. This was an important test of our implementation to risk communication through the Situated Learning Episode (EAS) methodology. Considering the numerous commitments and projects that usually involve schools, often refractory to activities that take several hours of lessons and extracurricular activities, there was a very large participation. Some products are also excellent attention grabber, with their ability to create a "Wow" factor, getting the conveyed message across and using entertainment similarly to advertising. As students have become good communicators, it means that they have acquired knowledge and reworked it, also developing critical thinking. The analysis of students' products reveals the effectiveness of the risk communication action and of the method of active learning we applied. The results encourage us to continue designing new EASs by means of this modern teaching methodology. Therefore, the enthusiasm shown by the teachers is a further incentive to continue experimenting new tools in support of digital school.

This experience is a good example of cooperation between School and Research for an integrated vision of economic and social development in agreement with the goals of the 2030 ONU Agenda for Sustainable Development. It also complies with the "National Indications" promoting the competences of active citizenship within the European Commission framework on Science education for responsible citizenship, Key competences for lifelong learning, and Skills Agenda for EU and Euridice Policies and Research on Science Teaching in European School in Europe [Piangiamore, 2019].

More than this, the results shown in this paper can be taken as a lesson learned to design future communication campaigns that effectively take into account the point of view of the target public.

Acknowledgments. This study was co-financed by the European Commission's Humanitarian Aid and Civil Protection (Grant agreement ECHO/SUB/2015/718655/PREV28). We are thankful to the schools and students that participated to Action E.3 "Know your school: be safe!" and to KnowRISK competition "Are you taking too much risk?". Special thanks to the jury members of the KnowRISK competition: M. Accardo and L. La Vecchia (University of Ferrara), M. Devecchi (University of Genova), F.R. Lugeri (University of Camerino), A. Croce (Istituto FIRC di Oncologia Molecolare - IFOM), C. Malgarotto (Order of Geologists of Liguria), C. Daidone (Command of the Fire Brigade of La Spezia), P. Cortopassi (Tuscany Region Seismic Sector of Massa), A. Nava (Parco Campo dei Fiori), R. Biondi, and D. Bertocchi.

We are grateful to A. Frione, P. Trolese, F. Bardelli, and S. Pedretti (Command of the Fire Brigade of La Spezia) for their precious contribution to focus groups at school and the INGV secretary (D. Piccarreda). Regarding the twinning between pilot schools in Italy and Portugal in the A.S. 2015-16: the headmaster M. Torre and the teachers G.M. Bartoletti, E. Milazzo, P. Biondi, and L. Rolla of the Middle school “J. Piaget” of La Spezia, the "Padre António Vieira" school of Lisbon and the KnowRISK team. Many thanks to all the school heads, teachers, and students involved in the experimentation of the KnowRISK-EAS in Italy: the Middle school “J. Piaget” and “U. Mazzini” of La Spezia, "F. Poggi” of Lerici and "P. Mantegazza” of San Terenzo, "G. B. Monteggia” of Laveno Mombello (Varese), the Scientific Lyceum and the Classic Lyceum "ParentuccelliArzelà" of Sarzana. Many thanks to the students A. Tedesco and B. Bertinotti with the prof. G.M. Bartoletti from La Spezia for taking part in the round table and the dissemination event of the final KnowRISK meeting in Lisbon. 


\section{Giovanna Lucia Piangiamore et al.}

\section{References}

Abrami, P.C., R.M. Bernard, E. Borokhovski, D.I. Waddington, A. Wade and T. Persson (2015). Strategies for Teaching Students to Think Critically: A Meta-Analysis, Rev. Educational Res., 85, 2, 275-314.

Arsalidou, M. and J. Pascual-Leone (2016). Constructivist developmental theory is needed in developmental neuroscience, npj Science Learn, 1, 16016, doi.org/10.1038/npjscilearn.2016.16.

Bamber, P. and L. Hankin (2011). Transformative learning through service-learning: no passport required. Transformative Learning Through Service-learning, 53, 2/3, 190-206, doi.org/10.1108/00400911111115726.

Bandecchi, A.E., V. Pazzi, S. Morelli, L. Valori and N. Casagli (2019). Geo-hydrological and seismic risk awareness at school: Emergency preparedness and risk perception evaluation, Int. J. Disaster Risk Reduction, 40, 101280, doi.org/10.1016/j.ijdrr.2019.101280.

Bergmann, J., and A. Sams (2012). Flip Your Classroom: Reach Every Student in Every Class Every Day 120-190, Washington DC: International Society for Technology in Education.

Borgers, N., Edith De Leeuw, and Joop Hox (2000). Children as Respondents in Survey Research: Cognitive Development and Response Quality, Bulletin of Sociological Methodology/Bulletin de Méthodologie Sociologique, 66, 1, 60-75, doi.org/10.1177/075910630006600106.

Calvi, P., M. Moratti and A. Filiatrault (2015). Studio della risposta di elementi non strutturali di edifici scolastici soggetti ad eventi sismici, Progettazione Sismica, 3-2015.

Cardona, O.D. (2007). Curriculum adaptation and disaster prevention in Colombia, in International Perspectives on Natural Disasters: Occurrence, Mitigation, and Consequences, edited by Stoltman, J., P. Lidstone, J. Dechano, L., Springer and M. Dordrecht, 397-408, doi.org/10.1007/978-1-4020-2851-9 22.

Crescimbene, M., N.A. Pino and G. Musacchio (2018) Risk Perception and Knowledge: the construction of the Italian questionnaire to assess the effectiveness of the KnowRISK Project actions. In: R. Rupakhety, S. Olafsson and B. Bessason, Proceedings of the International Conference on Earthquake Engineering and Structural Dynamics, Geotechnical, Geological and Earthquake Engineering, Springer International Publishing AG, 47, 471-485, https://doi.org/10.1007/978-3-319-78187-7_35.

Dweck, C. S. (2006). Mindset, New York: Random House.

Dunn, J. (2014). The 6-step guide to flipping your classroom, Retrieved from http://dailygenius.com/flipped.

Euridyce (2006). Science Teaching in School in Europe: Policies and Research, Brussels.

European Commission (2015). Science education for responsible citizenship, Brussels: Directorate-General for Research and Innovation, Science with and for Society.

European Commission (2006). Key competences for lifelong learning, Recommendation 2006/962/CE.

European Commission (2016). Skills Agenda for Europe.

GADRRRES (2017). Comprehensive School Safety Framework, http://gadrrres.net/resources/comprehensive-schoolsafety-framework.

GADRRRES, Global Alliance for Disaster Risk Reduction and Resilience in the Education Sector, GADRRRES, Comprehensive school safety (2017). Retrieved from, https://www.unisdr.org/we/inform/publications/51335.

Flipped Learning Network (FLN) (2014). The Four Pillars of F-L-I-P ${ }^{\text {тм }}$.

Mutch, C. (2015). Leadership in times of crisis: dispositional, relational and contextual factors influencing school principals’ actions, Int. J. Disast. Risk Re., 14, 186-194, doi.org/10.1016/j.ijdrr.2015.06.005.

Neubert, S. (2001). Pragmatism, constructivism and the theory of culture, in John Dewey between Pragmatism and Constructivism, L.A. Hickman, S. Neubert, K. Reich (eds), American Philosophy. Fordham Univ. Press, 162-184.

Transforming our world: the 2030 ONU Agenda for Sustainable Development, 2015.

Jenkins, H. (2010). Culture partecipative e competenze digitali. Media education per il XXI secolo (a cura di Ferri, P. and A. Marinelli). Guerini e Associati, IBS.

King, K.P. (2005). Bringing transformative learning to life, Malabar, FL: Krieger.

Lam, S., J. Law and R. Cheung (2004). The effects of competition on achievement motivation in Chinese classrooms, British Journal of Educational Psychology, 281-296 (16).

Musacchio, G., S. Falsaperla, S. Solarino, G.L. Piangiamore, M. Crescimbene, N.A. Pino, E. Elena, D. Reitano, F.M. Manzoli, M.F. Fabbri, M.B. Butturi and M.A. Accardo (2019). KnowRISK on Seismic Risk Communication: The Set-Up of a Participatory Strategy- Italy Case Study. Springer International Publishing AG, part of Springer Nature. http://hdl.handle.net/2122/11997. 
Osborne, J. and J. Dillon (2008). Science Education in Europe: Critical Reflections, 13. London: The Nuffield Foundation.

Piangiamore, G.L. (2019). Metodologie didattiche innovative di educazione dei rischi naturali nei progetti per le scuole del territorio spezzino, in "Comunicare il rischio, il rischio di comunicare", in De Pascale F., Farabollini P. \& Lugeri F.R. (eds). PRISMA - Economia, Società, Lavoro - IRES Marche. F. Angeli Ed., 113-133. 2019.

Musacchio, G., E. Eva and G.L. Piangiamore (2018a). The KnowRISK Action for Schools: A case study in Italy. In: R. Rupakhety, S. Olafsson and B. Bessason, Proceedings of the International Conference on Earthquake Engineering and Structural Dynamics, Geotechnical, Geological and Earthquake Engineering, Springer International Publishing, AG, 47, 459-471, https://doi.org/10.1007/978-3-319-78187-7_34.

Musacchio, G., S. Falsaperla, S. Solarino, G.L. Piangiamore, M. Crescimbene, N.A Pino, E. Eva, F. Manzoli, M. Fabbri, M. Butturi and M. Accardo (2018b). KnowRISK on Seismic Risk Communication: the set-up of a participatory strategy- Italy Case study. In: R. Rupakhety, S. Olafsson and B. Bessason, Proceedings of the International Conference on Earthquake Engineering and Structural Dynamics, Geotechnical, Geological and Earthquake Engineering, Springer International Publishing AG, 47,413-429, https://doi.org/10.1007/978-3-319-78187-7_31.

O’Neill, H., M.A. Ferreira, C.S. Oliveira, M. Lopes, S. Solarino, G. Musacchio, P. Candeias, M. Vicente and D. S. Silva (2018). KnowRISK Practical Guide for mitigation of seismic risk due to non-structural components. In: R. Rupakhety, S. Olafsson and B. Bessason, Proceedings of the International Conference on Earthquake Engineering and Structural Dynamics, Geotechnical, Geological and Earthquake Engineering, Springer International Publishing AG, 47, 309-323, https://doi.org/10.1007/978-3-319-78187-7_23.

Piangiamore, G.L., G. Musacchio and M. Devecchi (2016). Episodes of Situated Learning: Natural Hazards Active Learning in a Smart School, in Interactive Learning Strategies, Technologies and effectiveness, L. M. Hunt, Nova Science Publishers. New York, 21-45. ISBN 97881634841986.

Piangiamore, G.L., G. Musacchio, E. Eva and KnowRISK-Task E working group (2017). Know your school: be safe! where students become active part of the KnowRISK project, in $2^{\text {nd }}$ General Meeting KnowRISK Knowyour city, Reduce seISmic risKthrough non-structural elements, Catania 15-17 December 2016, Falsaperla, S., H. Langer, S. Mangiagli, L. Scarfî AA. VV. Editors, flipbook Miscellanea INGV: http://istituto.ingv.it/lingv/produzione-scientifica/miscellanea-ingv/.

Piangiamore, G.L., G. Musacchio and N.A. Pino (2015). Natural hazards revealed to children: the other side of prevention, in Peppoloni, S. \& G. Di Capua (eds), Geoethics: The Role and Responsibility of Geoscientists, Lyell Collection, Geological Society, London, Special Publications, 419, doi.org/ 10.1144/SP419.12.

Piangiamore, G.L., A. Pezzani and M. Bocchia (2012). ERiNat Project (Training on Natural Risks): from informed children to knowledgeable adults, in $7^{\text {th }}$ EUREGEO - EUropean congress on REgionalGEOscientific cartography and Information systems Proceedings, Bologna 12-15/6/2012, 1, 321-322.

Platt, S., G. Musacchio, M. Crescimbene, N.A. Pino, D.S. Silva, M.A. Ferreira, C.S. Oliveir and M. Lopes (2018). Development of a common (European) tool to assess earthquake risk communication. In: R. Rupakhety, S. Olafsson and B. Bessason, Proceedings of the International Conference on Earthquake Engineering and Structural Dynamics, Geotechnical, Geological and Earthquake Engineering, Springer International Publishing AG, 47, 493-510. https://doi.org/10.1007/978-3-319-78187-7_37.

Reeve, J. and E.L. Deci (1996) Elements of the competitive situations that affect intrinsic motivation, Personality and Social Psychology Bulletin, 22, 24-33.

Reitano D., S. Falsaperla, G. Musacchio G. and R. Merenda (2018). Awareness on Seismic Risk: How can Augmented Reality help? In: R. Rupakhety, S. Olafsson and B. Bessason, Proceedings of the International Conference on Earthquake Engineering and Structural Dynamics, Geotechnical, Geological and Earthquake Engineering, Springer International Publishing AG, 47, 485-493. https://doi.org/10.1007/978-3-319-78187-7_36.

Rivoltella, P.C. (2013). Fare didattica con gli EAS (Episodi di Apprendimento situato), Brescia, La Scuola.

Shindler, J. (2009). Examining the Use of Competition in the Classroom, in Transformative Classroom Management: Positive Strategies to Engage All Students and Promote a Psychology of Success, Chichester, United Kingdom.

Shiwaku, K., Y. Ueda, Y. Oikawa and R. Shaw (2016). School disaster resilience assessment in the affected areas of 2011 East Japan earthquake and tsunami, Nat. Hazards, 82, 333-365, doi.org/10.1007/s11069-016-2204-5.

Silva Almeida, L. and A. Helena Rodrigues Franco (2011). Critical thinking: Its relevance for education in a shifting society. Revista de Psicología (Lima), 29, 1, 175-195, Recuperado em 01 de julho de 2020, de http://pepsic.bvsalud.org/scielo.php?script=sci_arttext\&pid=S0254-92472011000100007\&lng=pt\&tlng=en. 


\section{Giovanna Lucia Piangiamore et al.}

Yeager, D.S. and C.S. Dweck (2012). Mindsets That Promote Resilience: When Students Believe That Personal Characteristics Can Be Developed. Educational Psychologyst, 47, 4), 302-314, Division 15, American Psychological Association ISSN: 0046-1520 print / 1532-6985, doi.org/10.1080/00461520.2012.722805.

Torosyan, R. (2007). Teaching for Transformation: Integrative Learning, Consciousness Development and Critical Reflection, Unpublished manuscript, https://web.archive.org/web/20060903101019/ http://www.faculty.fairfield.edu/rtorosyan/.

Uksw, S. (2014). Developing Critical Thinking Skills through School Teacher Training 'Training and Development Personnel' Model and Their Determinants of Success, Int. J. Info. Education Technol., 4, doi.org/ 10.7763/IJIET]

UNISDR (United Nations International Strategy for Disaster Reduction), Sendai Framework for Disaster Risk Reduction 2015-2030. UNISDR. Geneva (2015). Retrieved from, https://www.unisdr.org/files/43291_sendaiframeworkfordrren.pdf.

UNISDR (United Nations International Strategy for Disaster Reduction), Terminology on Disaster Risk Reduction UNISDR. Geneva (2009). Retrieved from, http://www.unisdr.org/we/inform/publications/7817.

UNISDR (United Nations International Strategy for Disaster Reduction), Towards a Culture of Prevention: Disaster Risk Reduction Begins at School. UNISDR (2006). Retrieved from, http://www.unisdr.org/2007/campaign/wdrc2006-2007.htm.

Verhoff, T. (1997). The Role of Competitions in Education, http://olympiads.win.tue.nl/ioi/ioi97/ffutwrld/competit.html. 